\title{
The $\alpha$-iso-cubebenol compound isolated from Schisandra chinensis induces p53-independent pathway-mediated apoptosis in hepatocellular carcinoma cells
}

\author{
JI EUN KIM ${ }^{1}$, SUN GUEN KIM ${ }^{2}$, JUN SUE GOO ${ }^{1}$, DA JEONG PARK ${ }^{2}$, YOU JIN LEE ${ }^{2}$, \\ IN SIK HWANG ${ }^{1}$, HAE RYEON LEE ${ }^{1}$, SUN IL CHOI ${ }^{1}$, YOUNG JU LEE ${ }^{1}$, \\ $\mathrm{CHUNG}_{\mathrm{HUN} \mathrm{OH}}{ }^{3}$, YOUNG WHAN $\mathrm{CHOI}^{2}$ and DAE YOUN HWANG ${ }^{1}$
}

\begin{abstract}
Departments of ${ }^{1}$ Biomaterials Science, and ${ }^{2}$ Horticultural Bioscience, College of Natural Resources \& Life Science, Pusan National University, Miryang 627-706; ${ }^{3}$ School of Dentistry, Dankook University, Cheonan 330-714, Republic of Korea
\end{abstract}

Received March 29, 2012; Accepted May 25, 2012

DOI: $10.3892 /$ or.2012.1875

\begin{abstract}
Schisandra chinensis (S. chinensis) plants are extensively used because of their anticancer, anti-inflammatory, antioxidant and antihepatic activities. However, their active compounds remain to be clearly determined. In this study, we investigated the antitumor functions of $\alpha$-iso-cubebenol ( $\alpha \mathrm{IC})$ isolated from $S$. chinensis using HepG2 hepatocellular carcinoma cells. HepG2 cells were exposed to $\alpha \mathrm{IC}$ for $24 \mathrm{~h}$, and apoptosis was assessed using standard viability and cell proliferation assays, flow cytometry and western blotting. HepG 2 cell populations treated only with $340 \mu \mathrm{M}$ of $\alpha \mathrm{IC}$ showed markedly increased cell death, but lower concentrations induced minimal alterations of population viability and cell morphology. However, the results of flow cytometry showed that the majority of viable cells were undergoing apoptosis at all tested $\alpha \mathrm{IC}$ concentrations. Western blot analysis results revealed a significant and $\alpha \mathrm{IC}$ concentration-dependent reduction in the levels of the pro-caspase- 3 apoptotic protein and the Bcl-2 anti-apoptotic protein. In particular, the Bax pro-apoptosis protein and p53 (which regulates Bax expression) showed different expression patterns after the application of $\alpha \mathrm{IC}$ treatment to HepG2 cells. Bax expression was slightly increased in cells treated with the high concentration of $\alpha \mathrm{IC}$, while p53 expression was markedly
\end{abstract}

Correspondence to: Dr Dae Youn Hwang, Department of Biomaterials Science, College of Natural Resources and Life Science, Pusan National University, 50 Cheonghak-ri, Samnangjin-eup, Miryang-si, Gyeongsangnam-do 627-706, Republic of Korea

E-mail: dyhwang@pusan.ac.kr

Dr Young Whan Choi, Department of Horticultural Bioscience, College of Natural Resources and Life Science, Pusan National University, 50 Cheonghak-ri, Samnangjin-eup, Miryang-si, Gyeongsangnam-do 627-706, Republic of Korea

E-mail: ywchoi@pusan.ac.kr

Key words: $\alpha$-iso-cubebenol, anti-proliferation, apoptosis, Bcl-2, Bax, p53 reduced in a dose-dependent fashion, similar to that of Bcl-2. The results of this study suggest that $\alpha \mathrm{IC}$ is an anticancer drug candidate by virtue of its apoptotic induction abilities in hepatocellular carcinoma cells, which occur via a p53-independent pathway.

\section{Introduction}

The dried fruits of $S$. chinensis Baill, a member of the Magnoliaceae family, are used extensively in the traditional medicinal systems of Korea, China and Japan (1). In particular, these fruits have been employed in the treatment and prevention of some chronic diseases, including hepatitis and cancer $(2,3)$, which may result from damage to biomolecules by free radicals and reactive oxygen species. Additionally, the seeds and fruits of $S$. chinensis are enriched in lignans, and >40 lignans have been isolated from this plant (4).

$\alpha \mathrm{IC}$ and $\alpha$-iso-cubebene, which have very similar structures, were first purified from the dried fruits of $S$. chinensis using $n$-hexane (5). In an early study, nuclear magnetic resonance (NMR), mass spectrometry and circular dichroism results showed that the molecular formula of $\alpha$-iso-cubebene was $\mathrm{C}_{15} \mathrm{H}_{24} \mathrm{NH}_{4}$, and harbors a cubebene sesquiterpene skeleton (5). $\alpha$-iso-cubebene strongly stimulates intracellular calcium signaling and CXCL8 production in human neutrophils (5). This stimulation increases in a concentrationdependent manner, with maximal activity being evident at $\sim 200 \mu \mathrm{g} / \mathrm{ml} . \alpha$-iso-cubebene also attenuates the activities of adhesion molecules, including vascular cell adhesion molecule-1, E-selectin, and intracellular adhesion molecule-1 in tumor necrosis factor- $\alpha$-stimulated human vein endothelial cells (6). These features have revealed the potential of $\alpha$-isocubebene as an effective novel anti-inflammatory agent for the prevention and treatment of vascular diseases. However, the principal biological function of $\alpha \mathrm{IC}$ remains unclear, with the exception of the anti-inflammatory effect against bacterial infection or endotoxin recently reported by our group (7). The present study sought to clarify the function of $\alpha \mathrm{IC}$ in the context of therapy for hepatocellular carcinoma. 
Hepatocellular carcinoma is a primary malignancy of hepatocytes, and generally leads to death within 6-20 months. This disease is the fifth most common cancer in men and the eighth most common cancer in women worldwide (8). Cirrhosis of any etiology is a major risk factor for hepatocellular carcinoma (9). Approximately $80 \%$ of patients with newly diagnosed hepatocellular carcinomas have pre-existing cirrhosis in the liver, caused primarily by excessive alcohol use, as well as hepatitis B or $\mathrm{C}$ infection (10). The variety of therapeutic strategies for hepatocellular carcinoma include surgical resection and liver transplantation, although the treatment options available depend on the characteristics of the tumor $(11,12)$. However, in many cases the drugs available for hepatocellular carcinoma therapy carry some disadvantages, such as toxicity, that hinder their clinical application.

Presently, in an effort to identify more efficacious therapeutic compounds, we investigated the anti-tumor functions of $\alpha \mathrm{IC}$ newly isolated from $S$. chinensis using HepG2 hepatocellular carcinoma cells. Apoptosis in the $\alpha$ IC-treated cells was assessed using an established 3-[4,5-dimethylthiazol-2-yl]-2,5-diphenyl tetrazolium bromide (MTT; Sigma-Aldrich)-based assay and western blotting. The present results indicate that high concentrations of $\alpha \mathrm{IC}$ can induce significant cell death of hepatocellular carcinoma cells. Apoptosis induced by $\alpha \mathrm{IC}$ is not correlated with Bax and p53 protein.

\section{Materials and methods}

Preparation of $\alpha I C$ compound. The $\alpha \mathrm{IC}$ compound used in this study was prepared via the methods established in our laboratory (5). Lyophilized powders of $\alpha \mathrm{IC}$ were dissolved in dimethylsulfoxide (DMSO, Sigma Aldrich, St. Louis, MO, USA) to a final concentration of $4 \mathrm{mM}$.

Cell culture and treatment. HepG2 human hepatoblastoma cells were purchased from the Korean Cell Line Bank (Seoul, Korea). Cells were grown in monolayers in minimum essential medium (MEM; Gibco, Grand Island, NY, USA) supplemented with $10 \%$ fetal bovine serum (FBS; Invitrogen, Carlsbad, CA, USA) and antibiotics (100 U/ml penicillin and $100 \mu \mathrm{g} / \mathrm{ml}$ streptomycin; Gibco) during incubation at $37^{\circ} \mathrm{C}$ in a humidified incubator containing $5 \% \mathrm{CO}_{2}$ in air. All other chemicals were purchased from Sigma-Aldrich.

In order to evaluate the dose-dependent effects, a stock solution ( $4 \mathrm{mM}$ ) of $\alpha \mathrm{IC}$ was applied to the HepG2 cell line with different final concentrations (40,80, 160 and $320 \mu \mathrm{M})$ of $\alpha \mathrm{IC}$ for another $24 \mathrm{~h}$. Additionally, the time-dependent effects were analyzed in the HepG2 cells treated for different times $(3,6,12$ and $24 \mathrm{~h}$ ) with $320 \mu \mathrm{M}$ of $\alpha \mathrm{IC}$.

Assay of cell proliferation. HepG2 cells were seeded at a density of $4 \times 10^{4}$ cells $/ 200 \mu \mathrm{l}$ in the wells of 96 -well plates and were then grown for $24 \mathrm{~h}$ in a $37^{\circ} \mathrm{C}$ incubator. When the cells attained $70-80 \%$ confluence, they remained untreated (vehicle) or were exposed to 40, 80, 160 or $320 \mu \mathrm{M} \alpha \mathrm{IC}$ dissolved in DMSO for another $24 \mathrm{~h}$. Cell proliferation was determined using the tetrazolium compound MTT. After the supernatants in the $\alpha \mathrm{IC}$ - or vehicle-treated wells were discarded, $200 \mu \mathrm{l}$ of fresh MEM and $50 \mu \mathrm{l}$ of MTT solution $(2 \mathrm{mg} / \mathrm{ml}$ in phosphate buffered saline; PBS) were added to each well. The cells were then incubated in a $37^{\circ} \mathrm{C}$ incubator. The reduction of MTT to insoluble purple formazan dye crystals by viable cells was assessed in $220 \mu \mathrm{l}$ recovered after $4 \mathrm{~h}$. The formazan precipitate was dissolved in DMSO and the absorbance was directly read at $570 \mathrm{~nm}$ in the well using a SoftMax Pro5 spectrophotometer (Molecular Devices, Sunnyvale, CA, USA). Additionally, the data were analyzed in terms of cell number versus absorbance, allowing for the quantification of changes in cell proliferation.

Flow cytometry analysis. The percentage of cells undergoing apoptosis and dead cells were detected via staining with fluorescein isothiocyanate (FITC) Annexin V (BD Bioscience, Franklin Lakes, NJ, USA). HepG2 cells were seeded at a density of $2 \times 10^{6}$ cells in $100 \mathrm{~mm}$-diameter dishes and grown for $24-48 \mathrm{~h}$ in an incubator at $37^{\circ} \mathrm{C}$. When the cells attained $70-80 \%$ confluence, vehicle, $40,80,160$ and $320 \mu \mathrm{M}$ of $\alpha \mathrm{IC}$ were added to each culture dish and the cells were incubated for an additional $24 \mathrm{~h}$. The cells were harvested, washed twice in ice-cold PBS, and resuspended in $1 \mathrm{X}$ binding buffer at a concentration of $1 \times 10^{6}$ cells $/ \mathrm{ml}$. Cells $\left(\sim 1 \times 10^{5}\right)$ in $100 \mu$ l of solution were transferred to round-bottomed culture tubes. FITC Annexin V $(5 \mu \mathrm{l})$ was added to stain the cells. After $15 \mathrm{~min}$ of incubation at room temperature, $400 \mu \mathrm{l}$ of $1 \mathrm{X}$ binding buffer was added to each tube and each sample was analyzed with a FACS Calibur apparatus (BD Biosciences) within $1 \mathrm{~h}$.

Western blot analyses. HepG2 cells harvested from 100-mm diameter culture dishes were solubilized with $1 \%$ Nonidet P-40 in $150 \mathrm{mM} \mathrm{NaCl}, 10 \mathrm{mM}$ Tris $\mathrm{HCl}$ (pH 7.5), and $1 \mathrm{mM}$ EDTA, and supplemented with a protein inhibitor mixture (Roche, Basel, Switzerland). They were then centrifuged for $10 \mathrm{~min}$ at $10,000 \mathrm{x} g$ at $4^{\circ} \mathrm{C}$. The homogenized proteins were separated by $10 \%$ sodium dodecyl sulfate-polyacrylamide gel electrophoresis for $3 \mathrm{~h}$ and transferred to nitrocellulose membranes over $2 \mathrm{~h}$ at $40 \mathrm{~V}$. The membranes were then incubated with primary antibodies [anti-Bcl-2 (SC-7382), anti-Bax (SC-493), anti-p53 (SC-6243) and anti- $\alpha$-tubulin (Sigma-Aldrich), anti-caspase-3 (Cell Signaling Technology Inc.)] were used to detect Bcl-2, Bax, p53 and anti- $\alpha$-tubulin. Each antigen-antibody complex was visualized with a biotinylated secondary antibody (goat anti-rabbit)-conjugated horseradish peroxidase streptavidin Histostain-Plus Kit (Zymed, South San Francisco, CA, USA) diluted to $1: 1,500$ in PBS.

Statistical analysis. Tests for significance between the vehicleand $\alpha$ IC-treated groups were performed via one-way ANOVA tests of variance (SPSS version 10.10, SPSS Inc., Chicago, IL, USA). If a statistically significant difference was observed, the Student Newman-Keuls post hoc test was used. All the values are expressed as the means \pm standard deviation (SD). A $p<0.05$ was considered significant.

\section{Results}

Effects of $\alpha$ IC oncell proliferation. Several lignans isolated from S. chinensis induce anti-proliferative and anti-apoptotic effects in hepatic carcinoma cells (13). Thus, we initially attempted to determine whether $\alpha$ IC exhibited an anti-proliferative effect in HepG2 hepatocellular carcinoma cells by determining the cell viability using an established MTT-based assay. The 
A

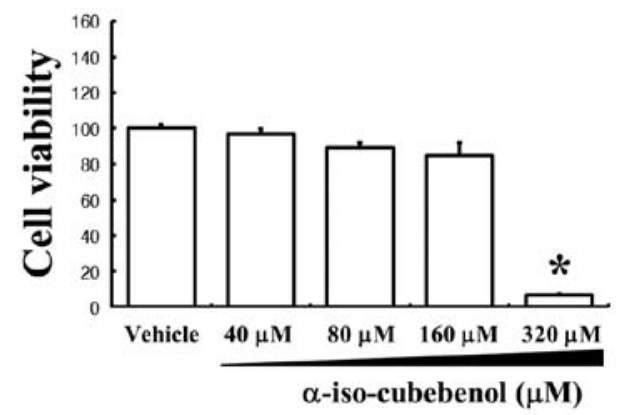

B

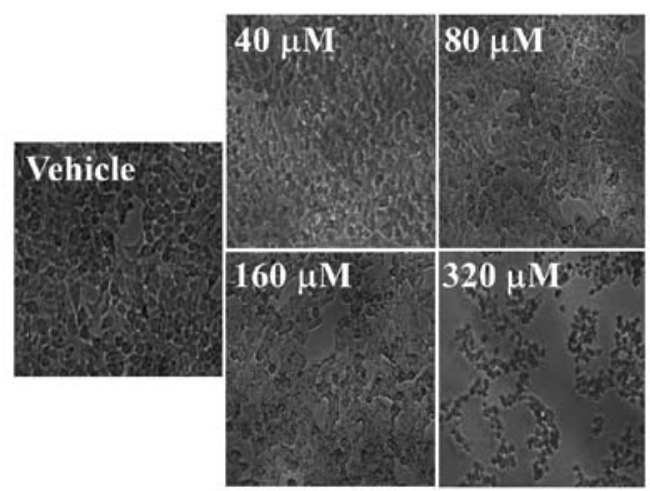

Figure 1. Dose-dependent effect of $\alpha \mathrm{IC}$ on anti-proliferative activity of HepG2 cells. Cells were cultured with $\alpha$ IC in DMSO at various concentrations for $24 \mathrm{~h}$. Vehicle-treatment was with DMSO only. (A) Cell proliferation activity was measured via an MTT assay. The values of the data represent the means \pm SD of three experiments. ${ }^{*} \mathrm{P}<0.05$ is the significance level as compared to the vehicle-treated group. (B) Microscopic images of HepG2 cells after $24 \mathrm{~h}$ of treatment with $\alpha \mathrm{IC}$ at various concentrations. Vehicle-treated cells were treated with DMSO. Cellular morphology was viewed at a magnification x20.

assay results confirmed that $\alpha \mathrm{IC}$ significantly induced cell death at $320 \mu \mathrm{M}$ (Fig. 1A). However, 40-160 $\mu \mathrm{M} \alpha \mathrm{IC}$ did not appreciably alter cell death. Additionally, HepG2 cells were observed via phase-contrast microscopy after $24 \mathrm{~h}$ of treatment with the same concentrations of $\alpha \mathrm{IC}$ to determine whether cell death was concurrent with cell morphological changes. $\alpha \mathrm{IC}$ concentrations of 40-160 $\mu \mathrm{M}$ did not affect HepG2 cell morphology, and these results were similar to those obtained with vehicle-treated cells. However, morphologically-altered cells in populations treated with $320 \mu \mathrm{M} \alpha \mathrm{IC}$ were markedly increased relative to other groups (Fig. 1B). Additionally, to investigate the anti-proliferative effects depending on the time, HepG2 viability was detected at various times after treatment with $320 \mu \mathrm{M} \alpha \mathrm{IC}$. Significant changes in the death of HepG2 cells were initially detected $12 \mathrm{~h}$ after $\alpha \mathrm{IC}$ treatment. At $24 \mathrm{~h}$ after $\alpha \mathrm{IC}$ treatment, more than $80 \%$ of HepG2 cells were detected as dead cells (Fig 2). Therefore, these results showed that high concentrations of $\alpha \mathrm{IC}$ and incubation for $24 \mathrm{~h}$ could effectively induce the death of hepatic carcinoma cells.

Effects of $\alpha I C$ on apoptosis. FITC Annexin V is used to quantitatively determine the percentage of cells within a population that are actively undergoing apoptosis $(14,15)$. In order to evaluate the effects of $\alpha \mathrm{IC}$ on apoptosis, HepG2 cells treated with various concentrations of $\alpha \mathrm{IC}$ were stained with FITC

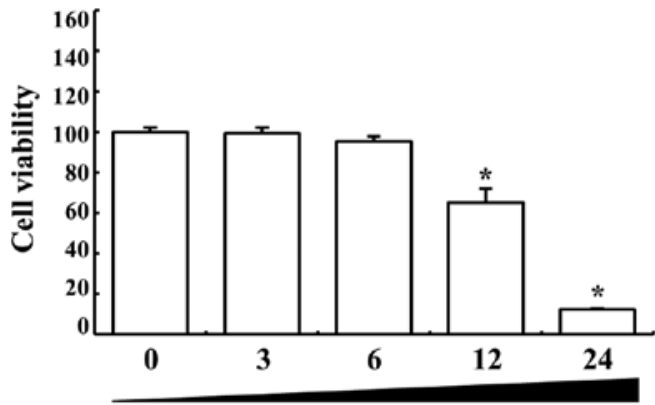

The time elapsed after treatment of $320 \mu \mathrm{M} \alpha$-iso-cubebenol (h)

Figure 2. Time-dependent effect of $\alpha \mathrm{IC}$ on anti-proliferative activity of HepG2 cells. Cells were cultured with $320 \mu \mathrm{M}$ of $\alpha \mathrm{IC}$ for different time and cell proliferation activity was measured via an MTT assay. The values of data are expressed as the means $\pm \mathrm{SD}$ of three experiments. ${ }^{*} \mathrm{P}<0.05$ is the significance level as compared to the vehicle-treated group.

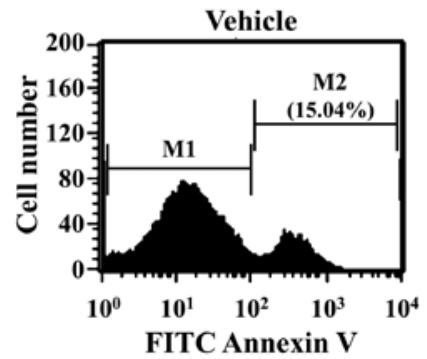

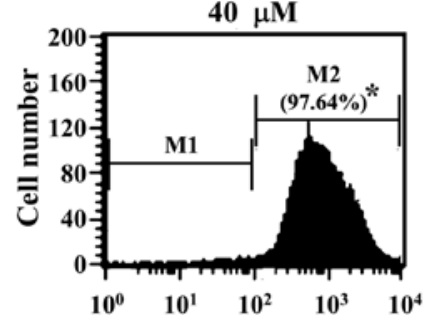

FITC Annexin V
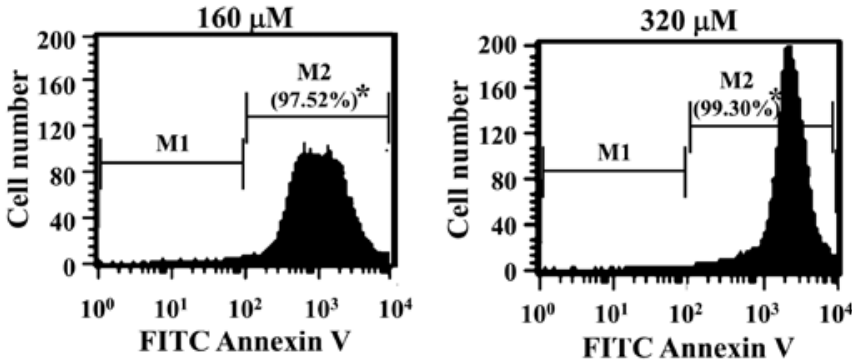

Figure 3. Identification of apoptotic cells. HepG2 cells were incubated with $\alpha \mathrm{IC}$ at various concentrations for $24 \mathrm{~h}$, then stained with FITC Annexin V to detect apoptotic cells. The fluorescence emitted from these cells was analyzed via flow cytometry. M1 denotes live cells and M2 denotes cells that are either undergoing apoptosis or are dead. The values are expressed as the means \pm SD of three experiments. ${ }^{*} \mathrm{P}<0.05$ is the significance level as compared to the vehicle-treated group.

Annexin V, and fluorescence was detected by flow cytometry. As shown in Fig. 3, $\alpha$ IC induced a significant increase in the number of cells undergoing apoptosis from 15 to $98-99 \%$ in $24 \mathrm{~h}$ in all treated groups. In particular, cells treated with $320 \mu \mathrm{M} \alpha \mathrm{IC}$ evidenced the highest numbers of apoptotic cells. 
A

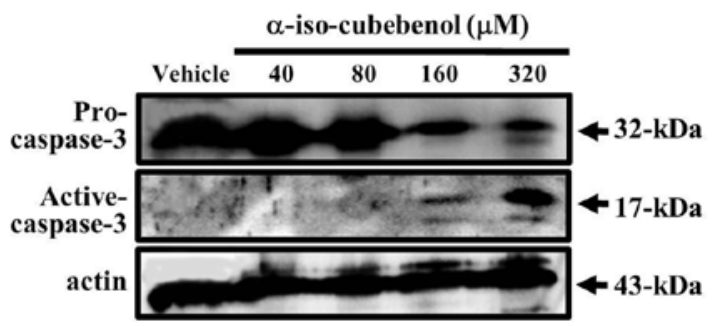

B
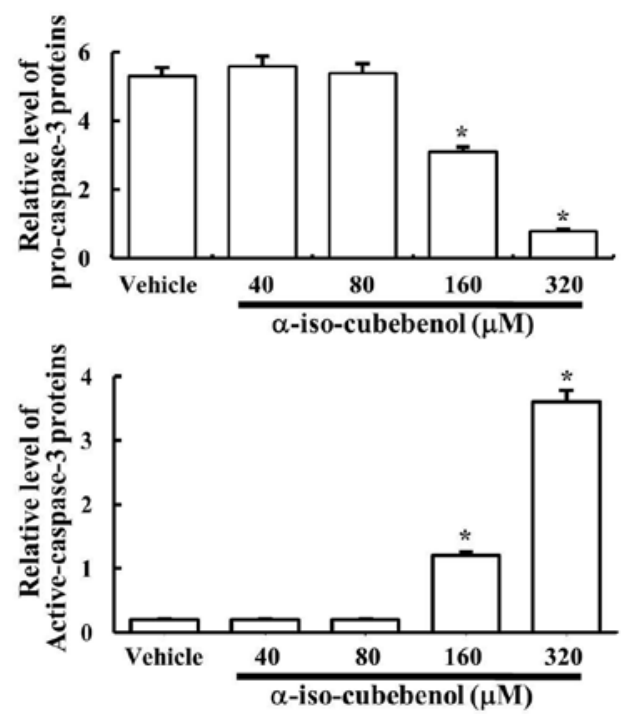

Figure 4. Effects of $\alpha \mathrm{IC}$ on the activation of caspase-3. Expression levels of the pro-caspase- 3 and active caspase- 3 proteins were analyzed via western blot analysis. The membranes were incubated with antibodies for caspase- 3 and $\beta$-actin proteins from HepG2 cells treated with various concentrations of $\alpha \mathrm{IC}$. Expression levels were quantified via an imaging densitometer and the sizes of the products are indicated. The data are expressed as the means $\pm \mathrm{SD}$ of three experiments. ${ }^{*} \mathrm{P}<0.05$ is the significance level as compared to the vehicletreated group.

Therefore, these results indicated that early events such as the loss of plasma membrane asymmetry in the apoptotic process may be induced by $\alpha \mathrm{IC}$ in the majority of treated cells, at all concentrations.

Furthermore, in order to demonstrate the activation of the apoptosis pathway, the cleavage of caspase- 3 was detected in HepG2 cells treated with various concentrations of $\alpha \mathrm{IC}$. Pro-caspase-3 levels were reduced significantly from the $160 \mu \mathrm{M}$-treated group to the $320 \mu \mathrm{M}$-treated group, whereas they were maintained in both the 40 - and $80 \mu \mathrm{M}$-treated groups. In particular, the reduction of pro-caspase-3 levels induced increases in the levels of active caspase-3, because the apoptosis signal induced the cleavage of pro-caspase- $3(32 \mathrm{kDa})$ into two small fragments (12 and $17 \mathrm{kDa}$ ) (16). The highest levels of active caspase- 3 were detected in the $320 \mu \mathrm{M}$-treated group (Fig. 4). Therefore, these results also confirmed that $\alpha \mathrm{IC}$ can activate caspase-3, a key regulator of the apoptosis process, at high concentration.

Effects of $\alpha I C$ on the apoptotic pathway. Bcl-2 belongs to the family of proteins that includes both pro- and anti-apoptotic
A

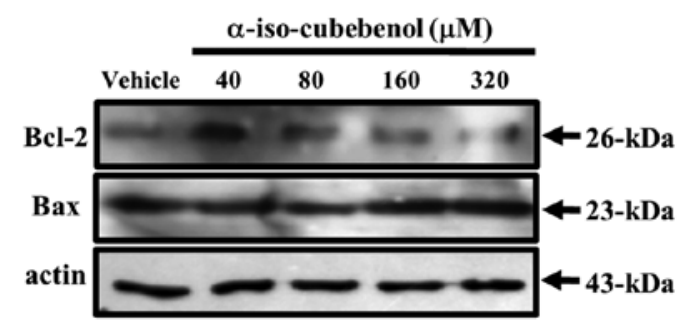

B
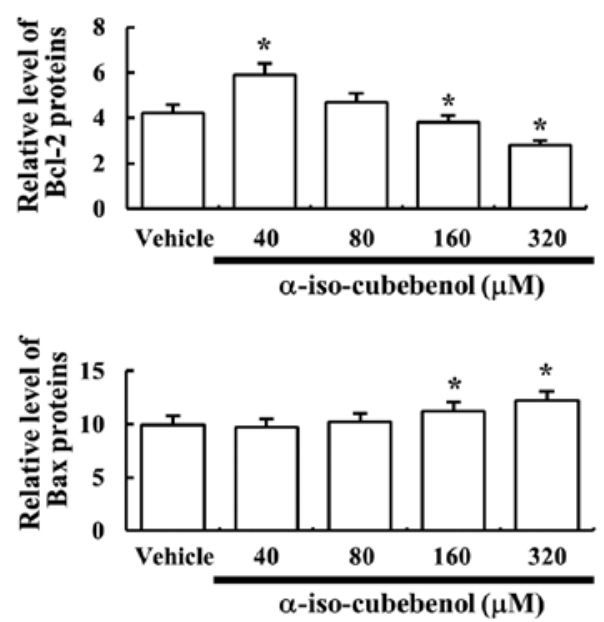

Figure 5. Effects of $\alpha \mathrm{IC}$ on the apoptotic pathway. Expression levels of the Bcl-2 and Bax proteins were analyzed via western blot analysis. The membranes were incubated with antibodies against Bcl-2, Bax and $\beta$-actin proteins from HepG 2 cells treated with various concentrations of $\alpha$ IC. Expression levels were quantified using an imaging densitometer and the sizes of the products are indicated. The data are expressed as the mean \pm SD of three experiments. ${ }^{*} \mathrm{P}<0.05$ is the significance level as compared to the vehicle-treated group.

members. Among these members, Bcl-2 proteins stimulate the anti-apoptotic process and the Bax protein significantly inhibits the anti-apoptotic actions of the Bcl-2 protein $(17,18)$. In order to assess the effects of $\alpha \mathrm{IC}$ treatment on proteins associated with the apoptosis signaling pathway, the expression levels of Bcl-2 and Bax proteins were determined in the vehicle and $\alpha \mathrm{IC}-$ treated groups using western blot analysis. The expression level of Bcl-2 protein was markedly increased only in the $40-\mu \mathrm{M} \alpha \mathrm{IC}$-treated group as compared to the vehicle-treated group, and the protein level gradually decreased in a dosedependent pattern. Cells treated with $320 \mu \mathrm{M} \alpha \mathrm{IC}$ exhibited the lowest level of Bcl-2 expression. Bax protein expression was increased slightly in a dose-dependent pattern. The highest level of this protein was observed in cells treated with $320 \mu \mathrm{M}$ $\alpha \mathrm{IC}$, although their levels were quite similar to those of the vehicle-treated group (Fig. 5). These results indicated that $\alpha$ IC could simultaneously induce the reduction of the protein levels associated with anti-apoptotic and the increase in protein levels associated with the pro-apoptotic process at high concentrations.

Effects of aIC on the expression of p53 tumor suppressor protein. The $\mathrm{p} 53$ protein is considered an important regulator in the mechanism of apoptosis (19). In particular, the upregulation 
A
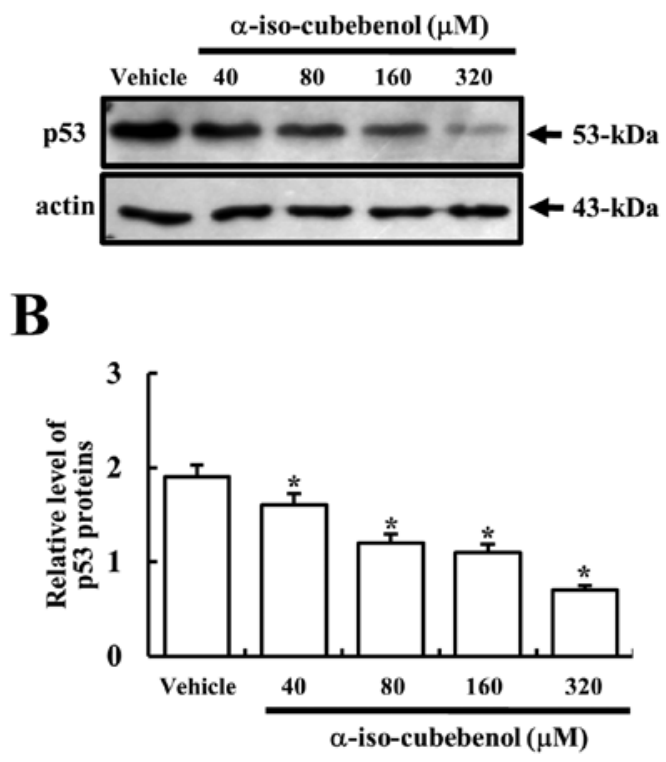

Figure 6. Effects of $\alpha \mathrm{IC}$ on the expression level of p53 tumor suppressor protein. The expression levels of $\mathrm{p} 53$ proteins were analyzed via western blot analysis. The membranes were incubated with antibodies for $\mathrm{p} 53$ proteins and the $\beta$-actin proteins from the HepG2 cells with various concentrations of $\alpha \mathrm{IC}$ Expression levels were quantified using an Imaging densitometer and the sizes of the products are indicated. The data are expressed as the means \pm SD of three experiments. " $\mathrm{P}<0.05$ is the significance level compared to the vehicletreated group.

of Bax is stimulated by activated p53 (20). Therefore, in order to determine whether the p53 tumor suppressor protein would be affected by $\alpha \mathrm{IC}$ in HepG 2 cells, the expression levels of $\mathrm{p} 53$ protein were assessed in the vehicle- and $\alpha \mathrm{IC}$-treated groups. The highest levels of p53 expression were detected in vehicletreated cells. After $\alpha \mathrm{IC}$ treatment, the levels of p53 expression decreased gradually in a dose-dependent pattern. In particular, $320 \mu \mathrm{M} \alpha \mathrm{IC}$-treated HepG2 cells evidenced the lowest levels of p53 expression (Fig. 6). These results indicated that $\alpha \mathrm{IC}$ could induce a reduction in $\mathrm{p} 53$ associated with tumor suppression. Furthermore, the expression of p53 did not contribute to the upregulation of Bax protein in HepG2 cells.

\section{Discussion}

S. chinensis has a well-recognized history in traditional Chinese medicine. Also referred to as 'Chinese Magnolia', the plant is widely distributed throughout the Eastern regions of Siberia, China, Japan, and Korea (3). Over the past 20 years, many active lignans including Gomisin A, B, C, D, E, F, G, K3, N and J, Schisandrol B, Schisandrin, and Schisandrin $\mathrm{C}$ were isolated from this plant $(3,21)$. The ligands have four thrapeutic properties: adaptogenic action, hepatic protection, hepatic stabilization and hepatic regeneration. Adaptogenic action involves specific action mechanisms such as energizing, nervous system stimulation, oxygenation, immune-modulation, anti-oxidation and skin protection (3,22-25). Additionally, these lignans reduce hyperlipemia and significantly inhibit the development of arteriosclerosis (26). With regard to hepatic protection, the lignans are correlated tightly with the increase in the hepatic levels of ascorbic acid, as well as the inhibition of NADPH oxidization and lipid peroxidation, which occur as the consequence of the induction effect of the hepatic cytochrome P-450 enzymatic system of the microsome. These lignans also protect against the cholestasis induced by toxic substances (27-30). The aforementioned ligands contribute to the hepatic regeneration process via the induction of mRNA transcription for hepatocyte growth factor, as well as the stimulation of hepatocyte proliferation and increased blood flow to the liver. Additionally, in an effort to improve regenerative capacity via reduced glutation and the synthesis of hepatic glucogen, the addition of these lignans induces increases in the levels of mitochondrial hepatic glutation and mitochondrial reductase glutation activity $(31,32)$. However, relatively few functional studies have been conducted to investigate in detail whether the novel lignans isolated from S. chinensis influence cell death of the hepatocellular carcinoma cells in vitro. In this study, we investigated the novel function of $\alpha \mathrm{IC}$ on the apoptosis of hepatocellular carcinoma cells.

Lignans are the most common constituents of S. chinensis. The major lignans in European seeds are deoxyschisandrin (0.07-1.09\%), gomisin N (0.24-1.49\%), schisandrin (0.75-1.86\%), wuweizisu C (0.01-0.34\%) and gomisin A (0.13-0.90\%) (33). Furthermore, several $\mathrm{C} 18$ dibenzocyclooctadiene lignans isolated from $S$. chinensis evidence a variety of therapeutic activities involving anti-tumorigenesis $(34,35)$, anti-hepatocarcinogenesis (36,37), anti-hepatotoxic (38), anti-human immunodeficiency virus (39), anti-oxidant $(2,40)$, anti-inflammatory (35) and vascular relaxation (41) properties. Our laboratory previously evaluated the anti-cancer ability of a hexane extract of $S$. chinensis fruit indigenous to Korea, Japan and China (2). As part of an effort to identify new compounds, we recently purified two novel compounds- $\alpha \mathrm{IC}$ and $\alpha$-iso-cubebene-which have been employed in a variety of human disease therapies $(5,6)$. These compounds have profound potential for development as novel drugs in the treatment of infection and inflammation. However, only a relatively minimal body of literature regarding the pharmacological mechanisms of action of $\alpha \mathrm{IC}$ exists.

Apoptosis (programmed cell death) is characterized by certain morphological features involving the loss of plasma membrane asymmetry and attachment, the fragmentation and condensation of the nucleus, and the formation of cytoplasmic vesicles $(42,43)$. The loss of plasma membrane asymmetry is one of the earliest detectable features, and can be distinguished by Annexin V conjugated FITC $(44,45)$. We stained HepG2 cells with Annexin $\mathrm{V}$ to evaluate the novel functions of $\alpha \mathrm{IC}$ on hepatocellular carcinoma. Although significant cell death was detected only at high concentrations using an MTT assay and morphological analysis, the results of flow cytometry suggested that the majority of the living cells were undergoing apoptosis. Therefore, our results indicate that $\alpha \mathrm{IC}$ can markedly induce the apoptosis of HepG2 cells even after treatment at low concentrations.

Apoptosis plays a critical role in a variety of physiological processes during fetal development and in adult life. Defects in the apoptosis process can lead to the progression of many diseases involving progressive cell accumulation, as well as cancer (46). The apoptotic process involves many families of proteins. Among these, the Bcl-2 proteins are key to the induction of the anti-apoptotic process (46). This protein is overexpressed in many solid tumors, and contributes to 
chemotherapy resistance and radiation-induced apoptosis $(46,47)$. Unlike many other known human oncogenes, Bcl-2 exerts its influence by enhancing cell survival rather than by stimulating cell division (47). In this study, we attempted to determine whether the expression level of Bcl-2 protein could affect $\alpha \mathrm{IC}$ treatment in hepatocellular carcinoma cells. As shown in Fig. 4, the expression of the Bcl-2 protein was markedly reduced with increases in the concentration of $\alpha \mathrm{IC}$. These results bear substantial similarities to the alteration pattern of apoptosis induced by other compounds, including gomisin $\mathrm{N}$ (13).

In addition, the Bax protein, another member of the $\mathrm{Bcl}-2$ family, inhibits the anti-apoptotic actions of Bcl-2. However, Bax may function as a classic tumor suppressor gene in vivo. Several human tumors involved the loss of functional mutations for this protein, and the knockout of the Bax gene induces tumorigenesis in mice (48-51). When we evaluated the effects of $\alpha \mathrm{IC}$ treatment on the expression level of Bax protein via western blotting, their expression was increased slightly at a high $\alpha \mathrm{IC}$ concentration. These results indicate that the effects of $\alpha \mathrm{IC}$ may be so minimal as to have a negligible effect on Bax expression.

Genetic mutations of the 553 gene are the most common alteration noted in hepatocellular carcinoma (52). Generally, the $\mathrm{p} 53$ protein functions as a transcriptional activator, which induces the transcription of many genes associated with cell metabolism. Among this variety of genes, apoptosis-related genes are considered important factors of the regulation process of balance between death and survival (53). In particular, Bax protein is a transcriptional target that can be regulated in response to a variety of p53-dependent apoptosis triggers. Zakaria et al (20) previously determined that the upregulation of Bax is stimulated by activated p53 after eurycomanone treatment. Although p53 activation is an important step in the regulation of apoptosis, the effects of p53 on the sensitivity of HepG 2 cells to $\alpha \mathrm{IC}$ have not been hitherto rigorously assessed. In this study, we showed that the expression levels of p53 were reduced dramatically by treatment with high concentrations of $\alpha \mathrm{IC}$. However, the expression level of Bax upregulated by activated p53 was slightly increased in HepG2 cells, as $\alpha$ IC was increased from 40 to $320 \mu \mathrm{M}$. Therefore, these results indicate that the apoptosis of HepG2 cells induced by $\alpha \mathrm{IC}$ is regulated via a p53-independent pathway.

All of the aforementioned results suggest that $\alpha \mathrm{IC}$ may be an excellent novel candidate for the therapeutic treatment of hepatocellular carcinoma. Furthermore, these compounds regulated the apoptotic process via a p53-independent pathway, which includes a slight increase in Bax expression and reduction in p53 expression. However, intensive work remains necessary to define precisely the role of this compound in inducing cell death of hepatocellular carcinomas for future clinical applications.

\section{Acknowledgements}

This study was supported by Technology Development Program for Agriculture and Forestry (106048031CG00).

\section{References}

1. Liu GT: Pharmacological actions and clinical use of Fructus schizandrae. Chin Med J 102: 740-749, 1989.
2. Choi YW, Takamatsu S, Khan SI, Srinivas PV, Ferreira D, Zhao J and Khan IA: Schisandrene, a dibenzocyclooctadiene lignan from Schisandra chinensis: structure-antioxidant activity relationships of dibenzocyclooctadiene lignans. J Nat Pros 69: 356-359, 2006.

3. Panossian A and Wikman G: Pharmacology of Schisandra chinensis Bail.: an overview of Russian research and uses in medicine. J Ethnopharmacol 118: 183-212, 2008.

4. Lu Y and Chen DF: Analysis of Schisandra chinensis and Schisandra sphenanthera. J Chromatogr A 1216: 1980-1990, 2009.

5. Lee YJ, Shim JW, Lee YJ, Park YH, Lee HY, Kim SD, Choi YW and Bae YS: Identification of a novel compound that stimulates intracellular calcium increase and CXCL8 production in human neutrophils from Schisandra chinensis. Biochem Biophys Res Commun 379: 928-932, 2009.

6. Choi YW, Kim HJ, Park SS, Chung JH, Lee HW, Oh SO, Kim BS, Kim JB, Chung HY, Yu BP, Kim CD and Yoon S: Inhibition of endothelial cell adhesion by the new anti-inflammatory agent alpha-iso-cubebene. Vascul Pharmacol 51: 215-224, 2009.

7. Lee YJ, Park SY, Kim SG, Park DJ, Kang JS, Lee SJ, Yoon S, Kim YH,Bae YS and Choi YW: Identification of a novel compound that inhibits iNOS and COX-2 expression in LPS-stimulated macrophages from Schisandra chinensis. Biochem Biophys Res Commun 391: 1687-1692, 2010.

8. Bosch FX, Ribes J, Díaz M and Cléries R: Primary liver cancer: worldwide incidence and trends. Gastroenterology 127: S5-S16, 2004.

9. Adami A, Hunter D and Trichopoulos D: Cancer of the liver and biliary tract. In: Textbook of Cancer Epidemiology. 2nd edition. Oxford University Press, Oxford, pp308-332, 2008.

10. El-Serag HB and Mason AC: Risk factors for the rising rates of primary liver cancer in the United States. Arch Intern Med 160: 3227-3230, 2000.

11. Bruix J and Sherman M: Management of hepatocellular carcinoma. Hepatology 42: 1208-1236, 2005.

12. Thomas MB and Zhu AX: Hepatocellular carcinoma: the need for progress. J Clin Oncol 23: 2892-2899, 2005

13. Yim SY, Lee YJ, Lee YK, Jung SE, Kim HJ, Kim JE, Kim HJ, Son BG, Park YH, Lee YG, Choi YW and Hwang DY: Gomisin N isolated from Schisandra chinensis significantly induces antiproliferative and pro-apoptotic effects in hepatic carcinoma. Mol Med Rep 2: 725-732, 2009.

14. Andree HA, Reutelingsperger CP, Hauptmann R, Hemker HC, Hermens WT and Willems GM: Binding of vascular anticoagulant alpha (VAC alpha) to planar phospholipid bilayers. J Biol Chem 265: 4923-4928, 1990.

15. Casciola-Rosen L, Rosen A, Petri M and Schlissel M: Surface blebs on apoptotic cells are sites of enhanced procoagulant activity: implications for coagulation events and antigenic spread in systemic lupus erythematosus. Proc Natl Acad Sci USA 93: 1624-1629, 1996.

16. Mazumder S, Plesca D and Almasan A: Caspase-3 activation is a critical determinant of genotoxic stress-induced apoptosis. Methods Mol Biol 414: 13-21, 2008.

17. Tsujimoto Y: Role of Bcl-2 family proteins in apoptosis: apoptosomes or mitochondria? Genes Cells 3: 697-707, 1998.

18. Tsujimoto Y and Shimizu S: Bcl-2 family: life-or-death switch. FEBS Lett 466: 6-10, 2000.

19. McKay BC, Ljungman M and Rainbow AJ: Potential roles for p53 in nucleotide excision repair. Carcinogenesis 20: 1389-1396, 1999.

20. Zakaria Y, Rahmat A, Pihie AH, Abdullah NR and Houghton PJ: Eurycomanone induce apoptosis in HepG2 cells via up-regulation of p53. Cancer Cell Int 9: 16, 2009.

21. Azzam HS, Goertz C, Fritts M and Jonas WB: Natural products and chronic hepatitis C virus. Liver Int 27: 17-25, 2007.

22. Chiu PY, Mak DH and Poon MK: In vivo antioxidant action of a lignan-enriched extract of Schisandra fruit and an anthraquinone-containing extract of Polygonum root in comparison with schisandrin B and emodin. Planta Med 68: 951-956, 2002.

23. Ko KM: Schisandrin B protects against tert-butylhydroperoxide induced cerebral toxicity by enhancing glutathione antioxidant status in mouse brain. Mol Cell Biochem 238: 181-186, 2002.

24. Nakamura K, Yoshida M and Uchiwa H: Down-regulation of melanin synthesis by a biphenyl derivative and its mechanism. Pigment Cell Res 16: 494-500, 2003.

25. Panossian AG: Effects of heavy physical exercise and adaptogens on nitric oxide content in human saliva. Phytomedicine 6: 17-26, 1999.

26. Yim TK and Ko KM: Schisandrin B protects against myocardial ischemia-reperfusion injury by enhancing myocardial glutathione antioxidant status. Mol Cell Biochem 196: 151-156, 1999. 
27. Baek MS, Kim JY and Myung SW: Metabolism of dimethyl-4,4'dimethoxy-5,6,5',6'-dimethylene dioxybiphenyl-2,2'-dicarboxylate (DDB) by human liver microsomes: characterization of metabolic pathways and of cytochrome P450 isoforms involved. Drug Metab Dispos 29: 381-388, 2001.

28. Iwata H, Tezuka Y and Kadota S: Identification and characterization of potent CYP3A4 inhibitors in Schisandra fruit extract. Drug Metab Dispos 32: 1351-1358, 2004.

29. Chang HF, Lin YH, Chu CC, Wu SJ, Tsai YH and Chao JC: Protective effects of Ginkgo biloba, Panax ginseng, and Schizandra chinensis extract on liver injury in rats. Am J Chin Med 35: 995-1009, 2007.

30. Ko KM, Ip SP, Poon MK, Wu SS, Che CT, Ng KH and Kong YC: Effect of a lignan-enriched fructus schisandrae extract on hepatic glutathione status in rats: protection against carbon tetrachloride toxicity. Planta Med 61: 134-137, 1995.

31. Chen N, Chiu PY and Ko KM: Schisandrin B enhances cerebral mitochondrial antioxidant status and structural integrity, and protects against cerebral ischemia/reperfusion injury in rats. Biol Pharm Bull 31: 1387-1391, 2008.

32. Kubo S, Ohkura Y, Mizoguchi Y, Matsui-Yuasa I, Otani S, Morisawa S, Kinoshita H, Takeda S, Aburada M and Hosoya E: Effect of Gomisin A (TJN-101) on liver regeneration. Planta Med 58: 489-492, 1992

33. He XG, Lian LZ and Lin LZ: Electrospray high performance liquid chromatography-mass spectrometry in phytochemical analysis of kava (Piper methysticum) extract. Planta Med 63: 70-74, 1997.

34. Chen DF, Zhang SX, Kozuka M, Sun QZ, Feng J, Wang Q, Mukainaka T, Nobukuni Y, Tokuda $\mathrm{H}$, Nishino $\mathrm{H}$, Wang HK, Morris-Natschke SL and Lee KH: Interiotherins C and D, two new lignans from Kadsura interior and antitumor-promoting effects of related neolignans on Epstein-Barr virus activation. J Nat Prod 65: 1242-1245, 2002.

35. Yasukawa K, Ikeya Y, Mitsuhashi H, Iwasaki M, Aburada M, Nakagawa S, Takeuchi M and Takido M: Gomisin A inhibits tumor promotion by $12-\mathrm{O}$-tetradecanoylphorbol-13-acetate in two-stage carcinogenesis in mouse skin. Oncology 49: 68-71, 1992.

36. Nomura M, Nakachiyama M,Hida T, Ohtaki Y, Sudo K, Aizawa T, Aburada M and Miyamoto KI: Gomisin A, a lignan component of Schizandora fruits, inhibits development of preneoplastic lesions in rat liver by 3'-methyl-4-dimethylamino-azobenzene. Cancer Lett 76: 11-18, 1994.

37. Ohtaki Y, Hida T, Hiramatsu K, Kanitani M, Ohshima T, Nomura M, Wakita H, Aburada M and Miyamoto KI: Deoxycholic acid as an endogenous risk factor for hepatocarcinogenesis and effects of gomisin A, a lignan component of Schizandra fruits. Anticancer Res 16: 751-755, 1996.

38. Wu MD, Huang RL, Kuo LM, Hung CC, Ong CW and Kuo YH: The anti-HBsAg (human type $B$ hepatitis, surface antigen) and anti-HBeAg (human type B hepatitis, e antigen) C18 dibenzocyclooctadiene lignans from Kadsura matsudai and Schizandra arisanensis. Chem Pharm Bull (Tokyo) 51: 1233-1236, 2003.
39. Chen DF, Zhang SX, Xie L, Xie JX, Chen K, Kashiwada Y, Zhou BN, Wang P, Cosentino LM and Lee KH: Anti-AIDS agents-XXVI. Structure-activity correlations of gomisin-Grelated anti-HIV lignans from Kadsura interior and of related synthetic analogues. Bioorg Med Chem 5: 1715-1723, 1997.

40. Lu H and Liu GT: Anti-oxidant activity of dibenzocyclooctene lignans isolated from Schisandraceae. Planta Med 58: 311-313, 1992.

41. Park JY, Lee SJ, Yun MR, Seo KW, Bae SS, Park JW, Lee YJ, Shin WJ, Choi YW and Kim CD: Gomisin A from Schisandra chinensis induces endothelium-dependent and direct relaxation in rat thoracic aorta. Planta Med 73: 1537-1542, 2007.

42. Bursch W, Ellinger A, Gerner C, Fröhwein U and SchulteHermann R: Programmed cell death (PCD): apoptosis, autophagic PCD, or others? Ann NY Acad Sci 926: 1-12, 2000.

43. Schwartz LM, Smitho SW, Jones MEE and Osborne BA: Do all programmed cell deaths occur via apoptosis? Proc Natl Acad Sci USA 90: 980-984, 1993.

44. Homburg CH, de Haas M, von dem Borne AE, Verhoeven AJ, Reutelingsperger CP and Roos D: Human neutrophils lose their surface Fc gamma RIII and acquire Annexin V binding sites during apoptosis in vitro. Blood 85: 532-540, 1995.

45. Koopman G, Reutelingsperger CP, Kuijten GA, Keehnen RM, Pals ST and van Oers MH: Annexin V for flow cytometric detection of phosphatidylserine expression on B cells undergoing apoptosis. Blood 84: 1415-1420, 1994.

46. Apakama I, Robinson MC, Walter NM, Charlton RG, Royds JA, Fuller CE, Neal DE and Hamdy FC: Bcl-2 overexpression combined with $\mathrm{p} 53$ accumulation correlates with hormone refractory prostate cancer. Br J Urol 74: 1258-1262, 1996

47. Joensuu H, Pylkkänen L and Toikkanen S: Bcl-2 protein expression and long-term survival in breast cancer. Am J Pathol 145: 1191-1198, 1994.

48. Baekelandt M,Holm R, Nesland JM, Tropé CG and Kristensen GB: Expression of apoptosis-related proteins is an independent determinant of patient prognosis in advanced ovarian cancer. J Clin Oncol 18: 3745-3747, 2000.

49. Harima Y, Nagata K, Harima K, Oka A, Ostapenko VV, Shikata N, Ohnishi T and Tanaka Y: Bax and bcl-2 protein expression following radiation therapy versus radiation plus thermoradiotherapy in stage IIIB cervical carcinoma. Cancer 88: 132-138, 2000.

50. Ito T, Fujieda S, Tsuzuki H, Sunaga H, Fan G, Sugimoto C, Fukuda M and Saito H: Decreased expression of bax is correlated with poor prognosis in oral and oropharyngeal carcinoma. Cancer Lett 140: 81-91, 1999.

51. Yin C, Knudson CM, Korsmeyer SJ and van Dyke T: Bax suppresses tumorigenesis and stimulates apoptosis in vivo. Nature 385: 637-640, 1997.

52. Fabregat I: Dysregulation of apoptosis in hepatocellular carcinoma cells. World J Gastroenterol 15: 513-520, 2009.

53. McGill G and Fisher DE: Apoptosis in tumorigenesis and cancer therapy. Front Bioscience 2: D353-D379, 1997. 